\title{
limiar da experiência estética: contribuições para pensar um percurso de subjetivação'
}

\author{
Marcos Villela Pereira*
}

Resumo: Este trabalho coloca em análise algumas concepções sobre arte, obra de arte, atitude estética e experiência estética com o intuito de propor o exercício da racionalidade estética como uma ampliaçáo da capacidade dos sujeitos para orientar sua percepção e compreensão ante as infinitas possibilidades da existência. A razão estética habilita o sujeito para que se concebam mundos náo apenas a partir de e/ou sobre esquemas referenciais, mas a partir de e sobre a experiência da presentificação do que existe, do ser-aí, da história efeitual e da desrealização dos limites estabelecidos pelas formas tradicionais de racionalidade. Postulo a ideia da experiência estética como uma oportunidade de ampliação, de desvelamento e de expansão da subjetividade na medida em que representa uma abertura para a coleção de exemplos que são a arte e a vida. A atitude estética é uma atitude desinteressada, é uma abertura, uma disponibilidade náo tanto para a coisa ou o acontecimento "em si", naquilo que ele tem de consistência, mas para os efeitos que ele pode produzir.

Palavras-chave: estética; experiência; experiência estética; arte; subjetivação.

\section{The threshold of aesthetic experience: contributions to think about a subjectivation journey}

Abstract: This article puts in question some views on art, artwork, aesthetic attitude and aesthetic experience in order to propose the exercise of aesthetic rationality extending subjective capacity to guide the perception and understanding regarding the infinite possibilities of existence. The aesthetic rationality empowers subjects to conceive not only worlds reduced at referencial schemes, but from and about experience of presentification of what exists, of being, of effectual history and of derealization of established limits on traditional rationality forms. I postulate the idea of aesthetic experience as an opportunity for expansion and disclosure of subjectivity in that it represents an opening to the collection of examples that consist in art and life. The aesthetic attitude is a selfless attitude, an openness, a willingness not so much for the thing or event "in itself ", in what it has consistency, but the effects it can produce.

Key words: aesthetics; experience; aesthetic experience; art; subjectivation.

\footnotetext{
Professor Titular do Programa de Pós-Graduação em Educação da Pontifícia Universidade Católica do Rio Grande do Sul (PUCRS), Brasil. Bolsista de Produtividade do CNPq, membro do Comitê Científico da ANPEd pelo GT-24, Educação e Arte.marcos.villela@pucrs.br

I. Este estudo deriva de pesquisa financiada pelo CNPq com Bolsa de Produtividade.
}

Pro-Posições, Campinas, v. 23, n. 1 (67), p. 183-195, jan./abr. 2012 
Pretendo apresentar algumas ideias e reflexóes que, mais do que apontar caminhos, permitam ampliar a discussão acerca do significado e do sentido do trabalho com as artes nas fronteiras do campo da educação. Mais especificamente, minha ideia é contribuir com alguns temas bastante caros à formação de professores de arte. Mais especificamente, pretendo ensaiar um confronto do tema do rigor na experiência estética, colocando em análise algumas concepçôes sobre arte, obra de arte, atitude estética e experiência estética.

Tomo como ponto de partida uma ideia bastante comum: a impossibilidade de definiçấo unívoca da arte. Ao longo da história da humanidade, temos presenciado calorosos debates sobre esse tema, sem nunca termos alcançado um conceito universal que silenciasse essa pergunta. Na Antiguidade, o campo da arte circundava as noçóes de imitação e beleza, passando pela sua utilização como elemento decorativo. No auge da modernidade clássica, a arte aproximou-se da sublimaçáo, do sublime. Na contemporaneidade, aderida antes ao conceito do que ao seu conteúdo expressivo estrito, a ideia de arte ampliou-se e ultrapassou os limites da inteligibilidade. Alcançou-se o patamar em que tratamos de diferentes formas de racionalidade em situação de simultaneidade e contingência e, portanto, caem por terra as iniciativas de circunscrever a arte às formas mais tradicionais ou universais de racionalização.

Vale dizer que já não se trata de perseguirmos alguma ideia de beleza como parâmetro. Também o belo, ao longo da história do pensamento, foi deslocado dos cânones que, pretensiosos e reducionistas, buscaram fixar seu significado. No começo, belo era o que imitava a realidade visível, era o que correspondia à repetição do paradigma naturalista e realista de representação. Depois, ele passou a ser tomado como sublimaçáo, como efeito tangível do sentimento oriundo da relação que nossa razão pura estabelecia com o mundo. Mais tarde, passou a ser um valor subjetivo, um sentimento singular proveniente de uma experiência única e individual que o sujeito tinha do mundo. Ou seja, assim como se passa com a arte, o belo foi deslocado do campo de possíveis estabelecido pelas formas tradicionais ou universais de racionalidade.

Por fim, podemos tentar perguntar pela utilidade da arte. Da mesma forma, veremos uma série de deslocamentos ao longo da história. No começo, a arte tinha por objetivo aproximar o homem do universo transcendente das divindades, dos deuses, do sobrenatural. Também podemos identificar, em algumas civilizaçóes, a arte com fins decorativos. Sob outro enfoque, podemos ver a arte assumir fins expressivos, comunicativos e representativos: a obra de arte pode expressar algo quando ela é a materialização ou a vivificação de uma ideia ou sentimento que apela ao seu criador para alcançar a existência; a arte pode comunicar algo quando sua materialidade é portadora de um conteúdo, quando ela veicula uma ideia, uma intenção, uma mensagem moral ou política; a arte pode representar algo quando, 
articulando sua potencialidade expressiva e comunicativa, significa algo, quando sua existência remete a algo que não está ali. Enfim, em termos de atribuição de utilidade, chegamos ao que nos disse Oscar Wilde, em 1891, no Prefácio ao seu Retrato de Dorian Gray (Wilde, 2000, p. 17): "toda arte é perfeitamente inútil". Ou seja, alcançamos a ideia de que a arte não serve para nada. Aliás, para explorar um pouco mais essa concepção, detenho-me no que diz esse autor. Segundo ele, "revelar a arte e ocultar o artista é a finalidade da arte" (idem, p. 17). Com essa ideia, ele inaugura a visão contemporânea da dimensão conceitual da arte e proporciona a compreensão da experiência com a obra de arte como uma experiência singular e subjetiva que pode bem ser individual ou coletiva, mas que definitivamente vai na direção da singularidade. E a singularidade, nesse caso, tanto pode ser a do artista quanto a do crítico ou, ainda, a do espectador. É arte o que eu digo que é arte. É arte o que eu faço ser arte. É arte o que eu torno arte. E, em última análise, ela serve para produzir efeitos de sentido no criador, no crítico e no público. Ou seja, a arte existe para produzir diferença no artista, no crítico e no público - não vindo ao caso, nesta circunstância, o juízo de valor sobre se essa é uma diferença para o bem ou para o mal, já que falamos aqui de singularidades.

Enfim, para esse autor

toda arte é, ao mesmo tempo, superfície e símbolo. Os que buscam sob a superfície fazem-no por seu próprio risco. Os que procuram decifrar o símbolo correm também seu próprio risco. $\mathrm{Na}$ realidade, a arte reflete o espectador e não a vida. (idem, p. 17)

Ou seja, não se trata de buscarmos decifrar a obra de arte como se houvesse nela um conteúdo essencial ou fundamental que devesse ser descoberto e revelado. $\mathrm{O}$ esforço pelo entendimento do que seja uma obra de arte como essência universal também cai por terra, sucumbindo à impossibilidade de circunscrição estanque em uma ou outra forma de racionalidade. O que nos resta, assim, é pautarmos nossa discussão pelas formas de operaçáo, uso, experiência e entendimento da obra de arte, procurando desviar a resposta da captura reducionista da definição, da classificação ou do julgamento. Ao contrário de perguntar o que é arte ou se isso é uma obra de arte, vale tomar em questáo a experiência de algum objeto, situação, acontecimento ou processo naquilo que ele tem em termos de potencial artístico, ou seja, naquilo que o configura como um acontecimento estético.

O risco de adentrarmos demasiadamente nessa regiáo especulativa é sermos aí capturados pelo vazio inconsistente da ideia de que, se nada é arte, entáo tudo é arte. O risco é vacilarmos na sedução que essa relativização provoca e fazermos desse relativo um absoluto. Por isso, importa-me adentrar um pouco mais em algumas ponderaçóes. 
Começo, aqui, pelo estabelecimento de uma condição de possibilidade para a experiência estética: a atitude estética. Para que se possa viver uma experiência estética, antes de tudo, é preciso assumir uma atitude estética, ou seja, assumir uma posição, uma postura que constitua e configure a nossa percepção. Não como uma intencionalidade, uma premeditação, uma antecipação racional do que está por vir, mas como uma disposição contingente, uma abertura circunstancial ao mundo. A premeditação é da ordem da atitude prática, utilitária, funcional, é quando nos dirigimos para o mundo com vistas a determinados fins, considerando as coisas e os acontecimentos como meios úteis para atingir esses fins.

A atitude estética é uma atitude desinteressada, é uma abertura, uma disponibilidade náo tanto para a coisa ou o acontecimento "em si", naquilo que ele tem de consistência, mas para os efeitos que ele produz em mim, na minha percepção, no meu sentimento. Tomo, aqui, o que postula Kant acerca do juízo estético. Segundo ele, quando apreciamos esteticamente, não se trata de simpatizar ou não com a existência da coisa, tampouco importa algo da sua existência, em termos daquilo que nos pode dizer o entendimento ou a explicaçáo (Kant, 1993, p. 49-50). Diferentemente disso, trata-se de contemplar ativamente a coisa, ou seja, atentar para o sentimento que a experiência da coisa produz em mim. $\mathrm{O}$ desinteresse reside na suspensão dos juízos explicativos que o sujeito poderia proferir ante a coisa ou o acontecimento que vive, de modo que possa colocar-se em uma posição de vulnerabilidade ao seu efeito. O juízo estético, nesse sentido, refere-se náo propriamente a um objeto ou acontecimento, puramente, mas ao sentimento que esse objeto ou acontecimento produz no sujeito. $\mathrm{O}$ interesse reduz o objeto ou o acontecimento à sua condição de bem de consumo ou veículo moral ou peça de coleção ou portador de uma mensagem, etc., impedindo-o de tornar-se o disparador de algo que não seja aquilo a que foi destinado pelo interesse.

A atitude estética, então, diz respeito à abertura que o sujeito tem ante o mundo. E essa atitude não se caracteriza por uma posição passiva nem ativa diante do objeto ou do acontecimento, mas por uma disponibilidade que o sujeito tem. Náo se trata de procurar submeter o objeto ou o acontecimento a certo esquema explicativo que poderia produzir um conceito, um juízo, uma definição ou uma ideia nem submeter-se a uma suposta essência ou fundamento que estivesse contida no objeto ou no acontecimento. Somos seres de encontro. Como nos diz Ortega-y-Gasset, nós somos nós e nossa circunstância; se não a salvamos, não salvamos também a nós. Portanto, não se pode polarizar a atitude no sujeito nem no objeto. Nós nos constituímos e constituímos o mundo realizando composiçôes e arranjamentos com a realidade circundante. A realidade, aquilo que existe (seja concreta e materialmente, seja abstrata e conceitualmente) não é mera exterioridade, mas algo que me constitui tanto quanto eu a constituo. Assim, não se trata de operarmos na dimensão da racionalidade que busca efetuar uma dominaçâo: não vou nem 
pretendo dominar a realidade nem ser dominado por ela. Náo se trata de efetuar uma razão que apreende, possui, define, nomeia, reduz ou entende a realidade. Trata-se, antes, de um jogo de mútua interferência, de composição de possibilidades que constituem sujeito e mundo. Do encontro e do arranjo entre sujeito e objeto ou acontecimento resulta algo que ainda não existia, resulta um efeito novo: um sentimento, um gosto, um estado que apenas existia enquanto possibilidade, como porvir. Ao entrar em jogo com o objeto ou o acontecimento, eles deixam de ser exteriores ao sujeito e passam a constituir o campo da experiência. E é aí que começa a criação, a experiência estética.

Podemos ter experiências estéticas com relação a qualquer objeto ou acontecimento, independentemente de ser arte ou não, de ser belo ou não, de existir concretamente ou não. Qualquer coisa pode ser um objeto estético se estabelecemos ante ele uma atitude estética. Podemos ter experiências estéticas ao entrar em jogo com uma música erudita, uma música popular, um som da natureza, um ruído urbano ou, mesmo, com o silêncio. Podemos ter experiências estéticas com uma pintura clássica, uma imagem sagrada, um desenho na parede de uma caverna, uma fotografia, um filme, um desenho na areia do chão, uma paisagem, uma cena urbana ou, mesmo, com uma imagem apenas imaginada ou sonhada. Podemos ter experiências estéticas sempre que adotamos uma atitude estética ante qualquer objeto da consciência (Stolnitz, 1960, p. 49). Essa condiçăo, entretanto, colocanos novamente diante de um dilema: a questáo do rigor da experiência estética. Se tudo pode ser objeto estético, se qualquer coisa pode sê-lo, qual é o critério para falarmos em experiência estética?

Aqui neste ponto, para dar conta de enfrentar essa questão, vou abordar a experiência estética primeiro do ponto de vista daquele que cria, o artista e, depois, do ponto de vista daquele que frui, o público.

A atividade criadora do artista implica algumas condiçóes e, dentre elas, destaco uma que considero básica: o domínio de uma linguagem, de uma técnica, de uma matéria é condição de possibilidade para a criação. A criação não é uma atividade espontânea. O fato de ser desinteressada não pode fazer dela uma abertura indefinida e incondicional. $\mathrm{O}$ desinteresse diz respeito à ideia de que não se trava uma relaçáo de dominação entre o sujeito artista e o mundo que o cerca e o constitui, mas que entre eles se produz uma zona de potência, um campo de possibilidades, o porvir de uma nova realidade.

Quando se produz um arranjo entre sujeito e mundo (entendido o mundo aqui como qualquer daquelas realidades - existentes ou não - a que me referi logo acima: uma música, o silêncio, uma paisagem, uma cena, um sentimento, um sonho) e esse arranjo gera um estado diferente, um potencial deslocamento no modo de ser do sujeito, uma vertigem, um embrulho no estômago, estamos falando do aparecimento do primeiro movimento de emergência da obra de arte. Uma 
experiência estética, nesses termos, assemelha-se ao estado de espírito daquele que se apaixona: no encontro com seu amado, inaugura-se um tipo de relação que não é de dominação, mas de composição, de arranjo, que desloca boa parte das referências que até então o constituíam e o projeta numa espécie de abismo. É aquele momento em que faltam palavras para dizer, para descrever. Falta matéria racional para explicar o que está se passando. Algo começa a existir em mim que não consegue via de expressão ou comunicaçáo conhecida. E esse algo me apela, me pede que o traga à existência, pede um corpo, uma materialidade, um substrato para existir. Então, é com esse sentimento novo, esse algo, que inicio um jogo compreensivo, uma dança que tem como propósito não o entendimento ou a explicação, mas a compreensão: a sensibilidade, a atenção, a percepção disso que, por enquanto, é só uma substância de conteúdo, ainda sem forma de expressão. Exercito a escuta perspicaz e meticulosa disso que me assola e que ainda náo tem nome. Perscruto isso que ainda é só movimento, isso que está pedindo vida, pedindo existência, pedindo expressão.

Dupla competência se me exige esse ponto. Competência de compreensáo e competência de expressão.

A competência da compreensão advém da experiência e pode ser aqui entendida como discernimento. Discernimento, segundo Gadamer, é mais que conhecimento, é algo "a que se chega" (Gadamer, 2008, p. 466). O conteúdo de verdade que produzimos pela experiência, justamente por seu caráter de realidade que se efetuou, de experiência que efetivamente aconteceu, remete sempre para novas experiências, ou seja, para todas as experiências que poderiam ter sido efetuadas, para todas as verdades que poderiam ter sido geradas ali. Nesse sentido, contrariando o senso comum, entendemos que experimentada é a pessoa que, justamente por ter tido as experiências que teve, está aberta a novas e inéditas experiências. Experimentado não é aquele que sabe, mas, ao contrário, aquele que está aberto ao porvir, ao que ainda náo sabe. $\mathrm{O}$ artista, nesse caso, tem a competência do discernimento porque sabe que aquilo que sabe é a evidência do limite do seu conhecimento, é a evidência da sua finitude, da sua mínima posição na história e na realidade que o circunda e o circunscreve. $\mathrm{O}$ artista pode ser entendido, nesse caso, como o menos dogmático possível porque teve tantas experiências, e já aprendeu tanto dessas tantas experiências, que isso o faz aberto e capacitado para voltar a ter experiências e com elas aprender (Gadamer, 2008, p. 465). O discernimento oriundo da experiência possibilita-nos a evidência de que as coisas não são apenas como supúnhamos em nossos exercícios explicativos e, dessa maneira, que as coisas experimentadas não cabem na matéria ou na forma expressiva tradicional. O discernimento, assim, é o que nos dá a capacidade de compreender o que se passa, é a tomada de consciência daquele algo que nos passa e para o qual ainda não temos palavras. O discernimento é, ao mesmo tempo, um quase-saber e um além-saber, é um pressentimento, é a 
faculdade que temos de conhecer pela negação: aproximamo-nos do que é pelo exercício de discernir o que não é.

A outra competência, da expressáo, diz respeito à prática. Ela é relativa ao domínio técnico e instrumental da matéria e da linguagem que, operadas, vão dar substância e forma à expressão. Ela advém do estudo, do domínio, do conhecimento e da prática de uma determinada linguagem, de uma técnica e de um material. Essa competência diz respeito à capacidade prática que um sujeito tem para operar com uma linguagem (a poesia, a literatura, a música, o desenho, a pintura, a dança, o teatro, a escultura, etc.), desenvolver um modo (romance, novela, soneto, aquarela, óleo, música tonal, atonal, modal, dança clássica, folclórica, etc.), utilizar um material (a língua, o som, a tinta, a pedra, o ferro, o corpo, etc.) e manejar uma ferramenta, um instrumento (a gramática, um violino, o lápis, um pincel, a voz, a câmera, enfim). Na medida em que aquele algo que emergiu na experiência estética pede existência, é necessário dominar com competência alguma via de expressão. A criação somente terá consistência se ancorada em uma matéria expressiva operada com rigor.

A livre-expressão é um exemplo da operação imprópria da matéria expressiva quando o sujeito dá vazão à atividade criadora sem a necessária competência no trato do material ou da linguagem que emprega. Apoiado numa suposta espontaneidade, ele mais faz catarse do que cria. Ainda que possamos aproximar a catarse da criação, não é esse o propósito aqui: antes, pretendo evidenciar a necessidade do rigor no processo de criação de uma obra de arte. Por exemplo, um sujeito só é capaz de improvisar em um campo no qual tenha um mínimo de competência: só posso improvisar uma música ao violão se souber minimamente tocar violão; só posso improvisar uma comida se souber cozinhar.

Enfim, concluindo minha especulação sobre a experiência estética do artista, torno a me referir à experiência que ele tem com essa quase-forma que um conteúdo inédito de sua existência faz assomar nele e que o convoca a criar. $\mathrm{O}$ artista fabrica a obra ao mesmo tempo que é fabricado por ela. E é essa obra, enquanto produto, que se dá a ver (ou ouvir ou presenciar ou assistir, etc.) para o público.

Assim, chego ao segundo polo anunciado. No caso do público, trato da experiência estética com algumas variaçóes. Igualmente, tomo como ponto de partida a necessária atitude estética, ou seja, uma atitude de abertura desinteressada ante os efeitos que a realidade de um objeto ou acontecimento pode produzir.

As obras de arte - sejam de que natureza forem - representam uma zona de confluência de possibilidades que foi trazida à vida pela operação de um artista e, por isso, representam um campo de potência ilimitado. Um objeto ou acontecimento cultural ou artístico não está aí meramente para ser compreendido, manejado ou dominado, mas, ao contrário, para ser experimentado. E isso significa que eles representam instâncias de convocação dos sujeitos, situaçóes de apelo ao jogo e à 
composição com o público que voltarão a dar existência à sua materialidade. Um livro, por exemplo, é apenas um livro: um objeto material com peso e dimensóes concretas que o tornam meramente uma coisa. Mas, ao ser aberto e lido, transforma-se, torna-se uma agência de novos sentidos que colocam em movimento o repertório e o universo daquele que lê. Assim, qualquer objeto artístico ou cultural: todos são e cada um é nada muito mais do que um amontoado de algo material - papel, pedra, corpos, letras, notas, dados, cores, etc. - até que entrem em composição ou arranjo com um sujeito que estabeleça com eles uma relaçáo estética e os transfigure em algo que eles apenas eram em potência. Todo objeto ou acontecimento é uma fonte inesgotável de possibilidades que abarca um infinito de sentidos, apesar de sua limitação material.

Por isso, trata-se de propor a atitude estética como uma abertura desinteressada. Movidos pelo interesse, nossa tendência é dominar (conceitual ou materialmente) as realidades que nos cercam e, nesse delírio de poder, furtamo-nos a possibilidade de sermos criativos. Entrar em jogo com um objeto ou acontecimento, de outro modo, representa conceder-se a possibilidade de, num único lance, configurar a experiência estética e ser configurado por ela. E aqui, da mesma maneira, confrontamo-nos com um dilema: se é possível produzir experiências estéticas com qualquer coisa, qual é a medida do rigor que se coloca para nós?

É bem verdade que podemos pensar na experiência estética que ocorre por arrebatamento, ou seja, que atropela o sujeito e o desloca radicalmente do campo de racionalidade que o circunscrevia. Nesse sentido, lembro do que nos diz Hilda Hilst sobre a potência da poesia:

"Um poema é como um soco. E, se for perfeito, te alimenta para toda a vida. Um soco certamente te acorda e, se for em cheio, faz cair a tua máscara, essa frívola, repugnante, empolada máscara que tentamos manter para atrair ou assustar" ela diz. (Hilst, 1998, p. 53)

Ou seja, podemos pensar na experiência estética involuntária, que pega o sujeito de sopetão, no susto. Mas, antes, importa-me tomar em questão a experiência intencional, aquela para a qual o sujeito se dispóe. $\mathrm{O}$ mundo cultural e artístico é constituído com formas de racionalidade próprias que implicam em formas de rigor específicas. Essas formas de racionalidade e rigor, por sua vez, só podem ser experimentadas quando se tem alguma competência para saber ler, ouvir, vivê-las. Saber operar minimamente com as diferentes linguagens é uma condição de possibilidade da experiência rigorosa. E, nesse sentido, a formação para a experiência estética passa pela ampliação da capacidade perceptiva, pela dotação de certa competência nas diferentes linguagens que permitam, justamente pela familiarização que se produz, uma suspensão dos juízos explicativos, abrindo espaço para 
a fruição e a experiência desinteressadas, para a abertura aos efeitos que o objeto ou o acontecimento podem produzir. Se me atenho ao impulso de decifração ou entendimento do objeto ou do acontecimento, torno a cair na armadilha de tentar dominá-los sob certa forma de racionalidade, impedindo-me de sentir os efeitos que esteticamente podem produzir. Da mesma forma, se me entrego "livremente" à experiência, também resvalo para o espontaneísmo catártico e leviano que resulta da frequente falta de rigor. A produção de sentidos que caracteriza a experiência estética é efeito do entrelaçamento, do arranjamento que o sujeito faz com o objeto ou com o acontecimento de maneira rigorosa, ou seja, levadas em consideração as possibilidades de compreensão que a experiência torna viáveis. E esse rigor responde à competência de perscrutar meticulosa e minuciosamente os pormenores do objeto, alcançando a sutileza da perspicácia que a discriminação e o discernimento conferem ao sujeito experimentado que, como já explorei acima, se constitui. O sujeito experimentado é não dogmático e, por isso, consegue suspender seus preconceitos, clichês e estereótipos justamente porque a experiência o confronta sempre com sua finitude, com a evidência do limite de sua interpretação. O que ele pensa sobre o que sente é sempre apenas uma das inumeráveis possibilidades de pensar ou de sentir. A formação do público, a formação do sujeito fruidor passa, assim, pela ampliaçáo de sua capacidade perceptiva, no sentido de mostrar as armadilhas da interpretação categórica e judicativa do gosto maniqueísta (bom versus mau, bonito versus feio, etc. ) e instigar o exercício da compreensão como uma tomada de atenção sobre os efeitos que a experiência pode produzir. Significa compreender que não gostar é, igualmente, uma forma de gostar. A formação do sujeito fruidor consiste em explorar diferentes maneiras de compreender a experiência estética, possibilitando uma abertura à diversidade de sentidos do mundo (ou seja, de formas de sentir a realidade).

Ampliar o repertório cultural, ampliar o repertório de experiências representa, assim, uma ampliação da capacidade de os sujeitos orientarem sua percepção e compreensão ante as infinitas possibilidades da existência. Inspirado por Thierry de Duve (2009, p. 50), ouso afirmar que a vida - como a arte - não se definem: a vida - e a arte - são uma coleção de exemplos. Nesse sentido, postulo a ideia da experiência estética como uma oportunidade de ampliação, de desvelamento e de expansão da subjetividade na medida em que representa uma abertura para essa coleção de exemplos.

Vale abrir, para finalizar, uma breve, mas nem por isso pouco importante digressão. Quero me referir à possibilidade da constituição da obra de arte a partir da experiência estética com objetos ou acontecimentos não artísticos, ou seja, não enquadrados nos cânones do que se considera arte, seja em que esfera for. E quero, nessa digressão, referir-me tanto à experiência do artista quanto à do crítico e à do público. Quero retomar aqui um aspecto que ficou pulsando em 
diferentes momentos deste ensaio: o fato de podermos ter experiências estéticas com qualquer coisa.

Para demarcar a gênese dessa possibilidade, tomo a proposição de Marcel Duchamp. Sua ideia de ready-made representa justamente a possibilidade de que qualquer objeto existente possa, ao ser deslocado de seu contexto, tornar-se disparador de uma experiência estética. Essa ideia desloca radicalmente a natureza da condiçáo estética para a atitude que se possa ter diante do objeto. Nessa medida, tanto o artista quanto o crítico ou o público têm a prerrogativa de transfigurar os objetos e os acontecimentos, convertendo-os em objetos estéticos. Mais uma vez, o mesmo dilema: se tudo pode, qual o limite?

Antonio Cícero lembra-nos que, assim como nas artes visuais, o ready-made levou muitos artistas e críticos de arte a considerarem obsoleta a arte de pintar ou esculpir; na poesia, ele levou muitos poetas e críticos literários a considerarem obsoleta a arte de fazer poemas (Cicero, 2005, p. 107). Ora, se abdicarmos do necessário rigor, também aqui caímos na inconsistência da experiência estética. Temos que ter presente que o fato de ser possível realizar experiências estéticas com qualquer coisa náo significa que se trata da mesma natureza de experiência: se somos capazes de ter uma experiência estética com o barulho do vento ou com o silêncio, isso não significa que podemos prescindir da música; se somos capazes de realizar uma experiência estética com um trocadilho, um anagrama, um trava-língua, uma parlenda ou uma frase recortada a esmo, não significa que podemos prescindir da poesia; se podemos realizar uma experiência estética com o bater de uma onda do mar em nossos pés ou com um pôr do sol, não significa que podemos prescindir da pintura ou do cinema. A experiência que podemos ter com uma peça de Bach, com uma música de Luis Gonzaga, com uma canção infantil, com o canto de um pássaro ou com o ruído de um trem não tem o mesmo valor. Sim, todas podem constituir-se experiências estéticas. Mas é inegável que há uma grande diferença de valor entre elas (ressalte-se que essa diferença não diz respeito a uma hierarquia - em que algo pode valer mais ou menos - mas que cada experiência inaugura ou diz respeito a uma ordem singular e irredutível a qualquer outra!). Podemos captar e experimentar esteticamente qualquer coisa, sim. E essas experiências sempre apresentam um grande potencial formativo para os sujeitos nelas implicados. Porque a experiência consiste, justamente, no deslocamento que sofremos da forma tradicional de racionalidade que nos circunscreve, colocandonos diante do inédito, da novidade da interpretaçẫo. $\mathrm{O}$ fato de termos produzido uma interpretação a partir de uma experiência é a evidência de que cada um que experimente o que experimentamos poderá produzir outra interpretação. Ademais, se chegamos a produzir uma interpretação, é porque infinitas outras interpretaçôes permanecem como interpretaçóes possíveis.

Assim, ante o mundo, temos a permanente e infindável possibilidade de transfigurar a realidade e sermos transfigurados por ela: Marcel Duchamp transfigura 
a realidade quando desloca o urinol ou a roda de bicicleta para uma exposição; Nuno Ramos transfigura a realidade quando expóe três urubus vivos na instalação Bandeira Branca, na 29쪼 Bienal de São Paulo; Frederico Moraes transfigura a realidade quando desloca os bordados e as coleçóes de Arthur Bispo do Rosário para uma galeria; Fausto Fawcett (2000) transfigura a realidade quando brinca com o anagrama Caroline Dickman - Nicole Kidman no poema "A fêmea camafeu"; uma criança transfigura a realidade quando monta num cabo de vassoura e sai cavalgando; um sujeito transfigura a realidade quando chora ante a visão do mar ou quando escuta uma sonata; um amante apaixonado transfigura a realidade quando, ante a insuficiência das palavras, faz silêncio ou grita ou beija ou abraça.

A medida do rigor, nesse caso, está no entendimento da intradutibilidade do conteúdo da experiência estética, ou seja, na impossibilidade de aquele algo que se produz no sujeito que experimenta esteticamente a realidade ser traduzido em alguma linguagem ou forma de racionalidade conhecida. Por ser intraduzível, a forma de expressão que vai dar concretude ao conteúdo da experiência estética precisa ser inventada. Uma imagem que bem representa essa situação, a meu ver, é a idéia do abismo. Como nos sugere Chantal Maillard, a experiência da criação e a experiência estética se assemelham à projeção em um abismo: tudo começa quando o mundo acaba. A experiência estética inicia quando tudo o que sei e tudo o que tenho sido já não bastam e o mundo apela por ser inventado. Ali onde, para as formas tradicionais de racionalidade, é o fim do mundo, porque não há palavras, não há forma possível de expressão, não há mais explicação, quando a gente náo entende mais nada, ali onde o mundo acaba é que começa o percurso e o processo de criação (Maillard, 1998, p. 252). Trata-se de aprender outra forma de racionalidade, a razão estética: aprender a viver conscientes das ficçóes que criamos; aprender a palpar o vazio - não o vazio como ausência, desaparecimento, fim ou morte de algo, mas, ao contrário, como origem, como porvir, como um perpétuo não-ser-mais ao lado de um não-ser-ainda, um não-ser-isso ou um não-ser-eu ao lado de um ser-quase.

Os efeitos da experiência estética - os valores, os sentimentos, os gostos, os juízos, as representaçôes, as categorias - são as modalidades das experiências que vão se modificando com a própria história, cujo núcleo é sempre essa estranha satisfaçáo que resulta do reconhecimento da capacidade de construir, de produzir sentidos que, quando a gente experimenta, ao mesmo tempo está construindo e produzindo a gente mesmo (Maillard, 1998, p. 254). A razão estética habilita o sujeito para que se construam mundos não apenas a partir de e sobre esquemas referenciais, mas, igualmente, a partir de e sobre a experiência da presentificação do que existe, do ser-aí, da história efeitual e da desrealização dos limites estabelecidos pelas formas tradicionais de racionalidade. Novamente, reitero a ideia de que o que existe não é passível de aprisionamento em uma definição, mas, de outro modo, o que existe é 
uma coleção incomensurável de exemplos. Cada sujeito - personagem da ficção, da memória ou do presente - representa uma forma de subjetivação possível.

Enfim. Concluo esta reflexão, esta provocação, com algumas citações que há muito me acompanham:

"O que é o belo, senão um grau suportável do terrivel?" (Rilke, 1988, grifo meu)

"Vai, vai, vai, disse o pássaro. O gênero humano não pode suportar tanta realidade. O tempo passado e o tempo futuro, o que poderia ter sido e o que foi, convergem para um só fim, que é sempre presente." (Eliot, 1981, grifo meu)

"A realidade sempre é mais ou menos do que nós queremos." (Pessoa, 2006, grifo meu)

E, por fim,

"No puedo hablar con $m i$ voz, sino con mis voces." "Não consigo falar com a minha voz, mas com as minhas vozes." (Pizarnik, 1993, grifo meu)

\section{Referências bibliográficas}

CICERO, A. Finalidades sem fim: ensaios sobre poesia e arte. São Paulo: Companhia das Letras, 2005.

DUVE, T. de. Cinco reflexóes sobre o julgamento estético. Revista Porto Arte, Porto Alegre, v. 16, n. 27 , nov. 2009.

ELIOT, T. S. Quatro quartetos, Burnt Norton. In: ELIOT, T. S. Poesia. Tradução de Ivan Junqueira. 3. ed. Rio de Janeiro: Nova Fronteira, 1981.

FAWCETT, F. A fêmea camafeu no país dos danados. In: CEP 20.000: o celeiro do underground carioca. Revista Trip, Rio de Janeiro, n. 83, 2000.

GADAMER, H.-G. Verdade e Método I - traços fundamentais de uma hermenêutica filosófica. 10. ed. Petrópolis: Vozes, 2008.

HILST, H. Cascos e carícias. São Paulo: Nankin, 1998.

KANT, I. Crítica da faculdade do juizo. Rio de Janeiro: Forense Universitária, 1993. [1793]

MAILLARD. C. La razón estética. Barcelona: Laertes, 1998.

ORTEGA Y GASSET, J. Meditaçôes do Quixote. São Paulo: Iberoamericana, 1967. p. 52.

PESSOA, F. Odes de Ricardo Reis. Porto Alegre: L\&PM, 2006.

PIZARNIK, A. Obras completas. Buenos Aires: Corregidor, 1993. 
RILKE, R. M. Elegias do Duino. Porto Alegre: Globo, 1988.

STOLNIZ, J. Aesthetics and the Philosophy of Art Criticism. Boston: Houghton Mifflin, 1960.

WILDE, O. Prefácio. In: WILDE, O. O Retrato de Dorian Gray. 4. ed. Rio de Janeiro: Civilização Brasileira, 2000. [1891]

Recebido em 22 de fevereiro de 2011 e aprovado em 04 de novembro de 2011. 